\title{
Letter in Reply [Response To Letter]
}

\author{
Michelle K Williams' \\ Monica R Butcher ${ }^{2}$ \\ Lisa J Merlo $\mathbb{D}^{3}$ \\ 'Department of Psychology, Indiana \\ University-Purdue University, Indianapolis, \\ IN, USA; ${ }^{2}$ Department of Pathology, Johns \\ Hopkins School of Medicine, Baltimore, \\ MD, USA; ${ }^{3}$ Department of Psychiatry, \\ University of Florida College of Medicine, \\ Gainesville, FL, USA
}

Correspondence: Lisa J Merlo

University of Florida College of Medicine,

PO Box 100256, I I 49 Newell Dr.,

Gainesville, FL, 326II, USA

Tel +I 3522944900

Email Imerlo@ufl.edu

\section{Dear editor}

We appreciate the authors' interest in our study, "Assessment of student perspectives on improving wellness in medical school: qualitative results from a cross-sectional survey of medical students in Florida,"1 which explored student preferences and recommendations with regard to medical school wellness programming and resources. We agree with Gupta and Raymond ${ }^{2}$ that student well-being should underpin all aspects of medical education, and we value the contribution of their unique perspectives as senior medical students from a different training environment. They acknowledged the representativeness of our study sample, and raised a common critique of qualitative studies. While quantitative studies use power calculations to determine the necessary sample size for a study, qualitative studies typically focus more on obtaining representativeness. We believe our sample met this metric because it was relatively large $(\mathrm{N}=864)$ and consisted of medical students from all medical schools within the state of Florida.

We agree that it would have been beneficial to obtain more demographic information from students, and acknowledged that this information could have served a useful role in contextualizing student responses. Unfortunately, we did not have approval from each of the participating schools to collect these data due to perceived threats to student anonymity based on the relatively low number of students from certain racial/ethnic backgrounds at some of the medical schools. Though we were unable to obtain detailed demographic information in the present study, we do believe that this information is important. Thus, we encouraged future research exploring demographic differences in order to ensure that wellness programs can meet the needs of students from all backgrounds.

We also acknowledge that assessing the available wellness resources and barriers to care at each medical school is an important step towards improving utilization of wellness resources, but doing so was beyond the scope of this study (particularly given the wide variability of services offered at different medical schools). Instead, we highlighted the fact that many students felt their schools should more actively advertise available services and work to improve access to these resources. We hope that sharing this information will inspire medical schools to examine their existing programs and identify ways to improve student awareness and access.

Another primary goal of the study was to inform medical schools of the breadth of student perspectives regarding ways to promote student well-being, in order to encourage a more comprehensive and creative approach to wellness resource development and implementation. We do not believe that medical schools should attempt to implement all of the students' recommendations, as we recognize that each medical school has different characteristics with regard to size, structure, 
make-up of the student body, access to broader university resources, and existing programs/services. However, by surveying students from a variety of schools, we hoped to capture the full continuum of student needs and preferences, so that all medical schools could use this information as a framework from which to examine the adequacy of their existing resources and/or obtain feedback from their own students about resources that are potentially important but lacking within their school. In the absence of internal feedback, relative prioritization of these recommendations could be achieved by referring to Figures 2 and 3 in our paper, ${ }^{1}$ which report the number of students who offered comments about each theme.

We further agree that the low rates of help-seeking among medical students in distress merits increased attention, and we reported on this issue in our original paper from the parent study. ${ }^{3}$ More work is clearly needed to increase student acceptance of available services, and the current study offers multiple suggestions from students that could help in this regard. In conclusion, we appreciate the opportunity to clarify these points and to further highlight the importance of assessing and addressing medical student views regarding ways to support student well-being as a critical component of their medical school experience.

\section{Disclosure}

The authors report no conflicts of interest in this communication.

\section{References}

1. Butcher MR, Thompson KM, Williams MK, Cooke BK, Merlo LJ. Assessment of student perspectives on improving wellness in medical school: qualitative results from a cross-sectional survey of medical students in Florida. Adv Med Educ Pract. 2021;12:1067-1079. doi:10.2147/AMEP.S323332

2. Gupta A, Raymond RJ. A response to "Assessment of student perspectives on improving wellness in medical school: qualitative results from a cross-sectional survey of medical students in Florida" [Letter]. Adv Med Educ Pract. 2021;12:1229-1230. doi:10.2147/AMEP. S343765

3. Merlo LJ, Curran JS, Watson R. Gender differences in substance use and psychiatric distress among medical students: a comprehensive statewide evaluation. Subst Abus. 2017;38(4):401-406. doi:10.1080/ 08897077.2017.1355871

Dove Medical Press encourages responsible, free and frank academic debate. The content of the Advances in Medical Education and Practice 'letters to the editor' section does not necessarily represent the views of Dove Medical Press, its officers, agents, employees, related entities or the Advances in Medical Education and Practice editors. While all reasonable steps have been taken to confirm the content of each letter, Dove Medical Press accepts no liability in respect of the content of any letter, nor is it responsible for the content and accuracy of any letter to the editor.

\section{Publish your work in this journal}

Advances in Medical Education and Practice is an international, peerreviewed, open access journal that aims to present and publish research on Medical Education covering medical, dental, nursing and allied health care professional education. The journal covers undergraduate education, postgraduate training and continuing medical education including emerging trends and innovative models linking education, research, and health care services. The manuscript management system is completely online and includes a very quick and fair peer-review system. Visit http://www.dovepress.com/testimonials.php to read real quotes from published authors. 